\title{
Renal Clearance to Total Clearance Ratio Measurement After Oral Dosing
}

National Cancer Institute

\section{Source}

National Cancer Institute. Renal Clearance to Total Clearance Ratio Measurement After

Oral Dosing. NCl Thesaurus. Code C154849.

The portion of total clearance attributed to the kidneys expressed as a percentage, following an oral dosing. 